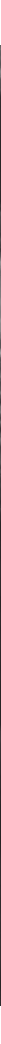

\title{
Inserción laboral de inmigrantes venezolanas, 2014-2019: ¿acumulación de desventajas?
}

Labor Market Insertion of Female Immigrants from Venezuela, 2014-2019: Accumulation of Disadvantages?

María Luz Moyano-Buitrago ${ }^{1}$

Universidad Nacional Autónoma de México, Ciudad de México, México

@mmoyano@comunidad.unam.mx

(D) https://orcid.org/0000-0002-6789-8041

Recibido: 10-11-2020 Aceptado: 22-01-2021 Publicado: 01-09-2021

1 Magíster en Desarrollo Económico y Políticas Públicas. 


\section{Resumen}

Desde 2014, Colombia experimenta una importante presencia de individuos provenientes de Venezuela a causa de la crisis en ese país. El objetivo de esta investigación es estudiar la inserción laboral de las mujeres venezolanas y evaluar si presentan desventajas acumuladas. Usando información de la GEIH para 2014-2019, este artículo compara algunos indicadores laborales de mujeres venezolanas en Colombia frente a locales y a otros grupos de inmigrantes. Los resultados indican que las venezolanas tienen probabilidad similar de estar ocupadas frente a otras mujeres, pero devengan ingresos más bajos, trabajan más horas, tienen menor probabilidad de pertenecer al sector formal y presentan condiciones laborales más precarias. Aunque el tiempo de asentamiento mejora sus resultados laborales, las brechas entre venezolanas y mujeres locales siguen siendo amplias. La evidencia sugiere que la población analizada experimenta acumulación de vulnerabilidades, por lo que es importante abordar futuros estudios a partir del enfoque de la interseccionalidad. Palabras clave: migración internacional; migración forzada; mujer y desarrollo; mercado de trabajo; Venezuela.

Clasificación JEL: B54, F22, J31, O15, R23.

\section{Abstract}

Since 2014, Colombia has experienced a significant presence of individuals coming from Venezuela due to the crisis in that country. The objective of this research is to study the labor market insertion of Venezuelan women and evaluate whether they present accumulated disadvantages. Using information from the GEIH for 2014-2019, this article compares some labor indicators of Venezuelan women in Colombia versus locals and other immigrant groups. The results indicate that Venezuelan women are similarly likely to be employed compared to other women, but receive lower incomes, work longer hours, are less likely to belong to the formal sector and have more precarious working conditions. Although the time of settlement improves their labor outcomes, the gaps between Venezuelan and local women remain wide. The evidence suggests that the population analyzed experiences an accumulation of vulnerabilities, which is why it is important to approach future studies from an intersectionality approach.

Keywords: international migration; forced migration; women and development; labor market; Venezuela.

JEL Classification: B54, F22, J31, O15, R23.

\section{Agradecimientos}

La autora agradece las oportunas observaciones de los dos dictaminadores del texto; al Dr. Israel Banegas (UNAM), a la Dra. Karina Videgain (UNAM) y al Dr. Curtis Huffman (UNAM) por su lectura a los borradores iniciales.

\section{Financiación}

Este trabajo hace parte de la agenda de investigación "Género y mercado laboral colombiano" (Doctorado en Economía, Universidad Nacional Autónoma de México) y está financiada por el Consejo Nacional de Ciencia y Tecnología (CONACYT, México) bajo el programa de becas doctorales a Posgrados de Calidad (PNPC).

\section{Conflicto de interés}

La autor a declara no tener ningún conflicto de interés en la publicación de este artículo.

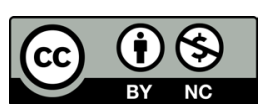

Este trabajo está bajo la licencía Atribución-No-Comercial 4.0 Internacional

¿Cómo citar este artículo?

Moyano-Buitrago, M. L. (2021). Inserción laboral de inmigrantes venezolanas, 20142019: ¿acumulación de desventajas? Sociedad y economía, (44), e10410743. https://doi. org/10.25100/sye.v0i44.10743 


\section{Introducción}

Desde el año 2013, Venezuela experimenta una crisis social, política y económica que ha provocado la salida de millones de personas de su territorio. Aun cuando muchos de estos migrantes manifiestan motivaciones económicas, esta migración presenta características distintivas de crisis de refugiados y de desplazamiento forzado; tales como salida masiva de migrantes en corto tiempo, búsqueda de seguridad física, psicológica y política en el exterior, bajos niveles de planificación y gran proporción de migrantes en condiciones de vulnerabilidad socioeconómica (World Bank Group, 2018). Además, dentro del territorio venezolano existen múltiples grupos con afectaciones desproporcionadas de violencia discriminatoria por considerárseles opositoras al Gobierno, como profesionales, comerciantes o empresarios susceptibles a extorsiones, así como miembros de minorías indígenas o individuos LGBTI que también demandan protección internacional, y a los que se les reconoce como desplazados (World Bank Group, 2018).

Para inicios de 2020 y, de acuerdo con la Agencia de la ONU para los Refugiados (ACNUR, 2020) ${ }^{2}$, después de Siria, Venezuela era el país con mayor generación de migrantes forzados, pues cerca de 3,6 millones de venezolanos habían sido desplazados al extranjero; y Colombia, por su parte, era el segundo país con mayor acogida de inmigrantes desplazados después de Turquía, con cerca de 1,8 millones de venezolanos en su territorio. La condición de desplazamiento forzado implica, además, la pérdida de derechos fundamentales como el derecho a migrar con dignidad y el derecho a insertarse en empleos no precarios en el mercado laboral de destino. Por ello, los desafíos en el mercado laboral pueden multiplicarse para quien llega con la carga de haber sido desplazado de forma no voluntaria (ACNUR, 2010).

Este artículo se enfoca en la discusión sobre los efectos que tiene el desplazamiento forzado en mujeres migrantes en edad de trabajar.

2 Los registros de datos de ACNUR cuentan con estándares de representatividad, fuentes primarias de información y actualización regular, aptos para informes estadísticos de índole descriptivo (ACNUR, 2020).
Su objetivo es analizar la inserción laboral en Colombia de las mujeres venezolanas y evaluar si, como refugiadas, son quienes presentan mayores desventajas por un proceso acumulativo de categorías sociales. A la par de las brechas en salarios, inserción y calidad en el empleo, la hipótesis de esta investigación se centra en que las mujeres que experimentan un desplazamiento forzado (para este caso, inmigrantes venezolanas) presentan un efecto acumulado de desventajas. Dentro del estudio, esta interseccionalidad se entiende como el resultado de la interacción entre sus diferentes condiciones, para este caso: género, estatus migratorio y características familiares; bajo un sistema social y de mercado incapaz de absorber la mano de obra y las necesidades de una población migrante en masa, generando escenarios propicios para las desventajas y mayores niveles de vulnerabilidad laboral en las migrantes venezolanas (Hankivsky, 2014). Además, la contribución de este texto es aportar evidencia de que la inserción de la mujer en el mercado de trabajo en Colombia ocurre dentro de una matriz de desigualdades sociales.

Aunado a ello, existen varias razones para esperar que las venezolanas tengan peores condiciones laborales que las mujeres locales y que las demás mujeres inmigrantes, particularmente aquellas que no experimentaron un desplazamiento forzado. Una de estas es que los migrantes forzados pueden tener experiencias diferentes a las presentadas por migrantes voluntarios, ya que, al ser una movilización planificada, estos últimos suelen moverse a partir de criterios de costobeneficio, mientras que los migrantes forzados son el resultado de situaciones fuera de su control y sus decisiones de movilización están principalmente motivadas por su seguridad y la de sus familias, incluso si la migración les implica peores condiciones laborales que las de su lugar de origen (Ruiz y Vargas-Silva, 2018; Becker y Ferrara, 2019). A partir de esta idea, la bibliografía sugiere que aquellos que experimentan la migración forzada tienen menos probabilidad de selección inicial en los mercados laborales de destino, en comparación con otros migrantes, así como experiencias iniciales de asimilación más complejas. 
El estudio de los efectos de las migraciones forzadas en el mercado laboral colombiano ha sido previamente estudiado, dado el fenómeno migratorio interno que experimentó el país con el conflicto armado, y el cual provocó un shock de oferta laboral que afectó a los mercados laborales locales (ej. Calderón et al., 2011; Calderón-Mejía e Ibáñez, 2016; Lozano-Gracia et al., 2010; Romero, 2013; Flórez, 2003; Morales, 2018; Ibáñez y Velásquez, 2008; Valencia y Montoya, 2019; entre otros). Sin embargo, el estudio de la migración venezolana en el mercado laboral colombiano cobra relevancia en tiempos recientes, y hasta el momento se ha enfocado en medir los efectos en el lugar de destino y los cambios en las condiciones laborales de la población no migrante (ej. Caruso et al., 2019; World Bank Group, 2018).

En relación a la selección de la población femenina como eje de estudio: a pesar de la evidencia empírica sobre las consecuencias de las migraciones forzadas, la investigación sobre su impacto en las mujeres es escaso. Ya que el desplazamiento forzado afecta diferencialmente a mujeres y hombres, y las estrategias para afrontarlo también son distintas, cobran relevancia los estudios que midan las brechas intra e intergénero (Calderón et al., 2011; Silva, 2012). Algunas investigaciones (ej. Silva, 2012; Del Carpio y Wagner, 2015; Accetturo e Infante, 2013) han encontrado que existen marcadas diferencias de género en la mayor parte de las categorías laborales dentro del estudio de poblaciones migrantes. Además, en estos mismos estudios se evidencia que, en la comparación entre grupos de migrantes discriminados por género, se presentan desventajas importantes para las mujeres, especialmente si fueron desplazadas forzadas o refugiadas, frente a hombres con la misma experiencia migratoria, o frente a otras mujeres en las investigaciones intragénero. Algunos autores como Calderón et al. (2011), Barone y Mocetti (2011), Dustmann y Schmidt (2000), Adsera y Chiswick (2007), PavajeauDelgado (2018), entre otros, han limitado también sus poblaciones de estudio al análisis de los colectivos de migrantes femeninos para ahondar en el estudio intra-grupo de una población ya evidenciada como vulnerable.
El estudio está guiado por cuatro principales preguntas: ¿existen diferencias laborales (en torno a la probabilidad de ocupación, ingresos por hora, formalidad y precariedad) entre mujeres sin experiencia migratoria reciente y grupos de mujeres inmigrantes en Colombia? ¿Existen diferencias laborales entre los grupos de inmigrantes? ¿Cuáles son los principales determinantes individuales y por hogar que explican las diferencias en los indicadores laborales? ¿Existe convergencia en los indicadores laborales de las inmigrantes recientes y las inmigrantes con más tiempo de asentamiento? Para responder a estas preguntas, se conformaron cuatro grupos de población de análisis: mujeres sin experiencia migratoria reciente o locales (mujeres en Colombia sin migrar en los últimos 5 años), migrantes venezolanas (nacidas en Venezuela), migrantes retornadas (colombianas que habían migrado a Venezuela y ahora regresan a Colombia) y migrantes colombianas internas.

El documento está organizado de la siguiente manera: en la sección 2 se presenta un contexto general de la crisis venezolana y sus efectos migratorios en Colombia; la sección 3 provee el marco analítico de referencia; la sección 4 describe los datos utilizados para el análisis, las características de los grupos de análisis, la descripción general de las principales variables y la metodología empleada; la sección 5 presenta los principales resultados del estudio; y la sección 6 , las conclusiones.

\section{Migración venezolana en Colombia}

Por años, el fenómeno migratorio entre Venezuela y Colombia ha estado fuertemente marcado por el dinamismo laboral y humanitario de sus fronteras, especialmente desde los fenómenos del desplazamiento y del refugio (deFlores, 2004). Sin embargo, a partir de 2014, la entrada masiva de inmigrantes venezolanos a Colombia ha significado un importante cambio en la dirección y tendencia migratoria de la región (World Bank Group, 2018). De acuerdo con cifras de la oficina de Migración Colombia (2020), al 30 de abril de 2020, de los 3,6 millo- 
nes de venezolanos que se han visto obligados a salir de su país, cerca de 1,8 millones residen en Colombia, $42 \%$ de manera regular y $58 \%$ de manera irregular. Desde el año 2014, después de la crisis, Colombia ha llegado a registrar tasas de crecimiento anuales de inmigración de cerca de $400 \%$, donde más del $95 \%$ corresponde a migración de origen venezolano. Esta migración tiene un perfil etario diverso. Las mujeres venezolanas representan el $49 \%$ de esta población. A partir de los datos de la Gran Encuesta Integrada de Hogares -GEIH- (DANE, $2014 ; 2015 ; 2016 a ; 2017 ; 2018 ; 2019$ ), en la Figura 1 se muestra el comportamiento de la inmigración femenina internacional en los últimos años. Esta gráfica refleja la tendencia general de la inmigración venezolana residente en Colombia, donde se puede evidenciar que el número de inmigrantes venezolanas ha incrementado paulatinamente en los últimos periodos.

A su vez, los colombianos que regresan desde Venezuela (inmigrantes retornados) empezaron a registrar importantes cifras de ingreso desde el inicio de la crisis, periodo en el cual empezó a hablarse de un primer shock de oferta laboral en Colombia proveniente del país vecino. A partir del año 2017, la migración de venezolanos de origen superó las cifras de retorno, aunque paralelamente, desde 2014, el país presentara una tendencia a la baja de la demanda laboral nacional, junto con una tendencia general al alza en la tasa de desempleo, rural y urbana, a lo largo del periodo analizado (Banco de la República de Colombia, 2019). Este importante registro de entrada migratoria al país ha significado la adaptación de los gobiernos locales a la creciente oferta de mano de obra, y la toma de medidas en materia migratoria y laboral a través del lanzamiento de diferentes programas de apoyo estatal como la Tarjeta de Movilidad Fronteriza (TFM) o el Permiso Especial de Permanencia (PEP) para garantizar el acceso de la población inmigrante al trabajo formal (Migración Colombia, 2020).

Estos importantes registros de tránsito migratorio desde Venezuela, en los últimos años, han cobrado relevancia en la investigación del mercado laboral colombiano, por lo que estudios recientes se han enfocado en medir los efectos en los mercados laborales locales, tanto rurales como urbanos, así como los cambios en las condiciones laborales de la población no migrante, encontrando principalmente consecuencias negativas para el mercado colombiano, tales como efectos en los salarios informales y de poca cualificación, cambios en las percepciones de seguridad, afectaciones sobre los niveles de pobreza, entre otros (Caruso et al., 2019; World Bank Group, 2018).

Figura 1. Migración femenina internacional en Colombia 2014-2019

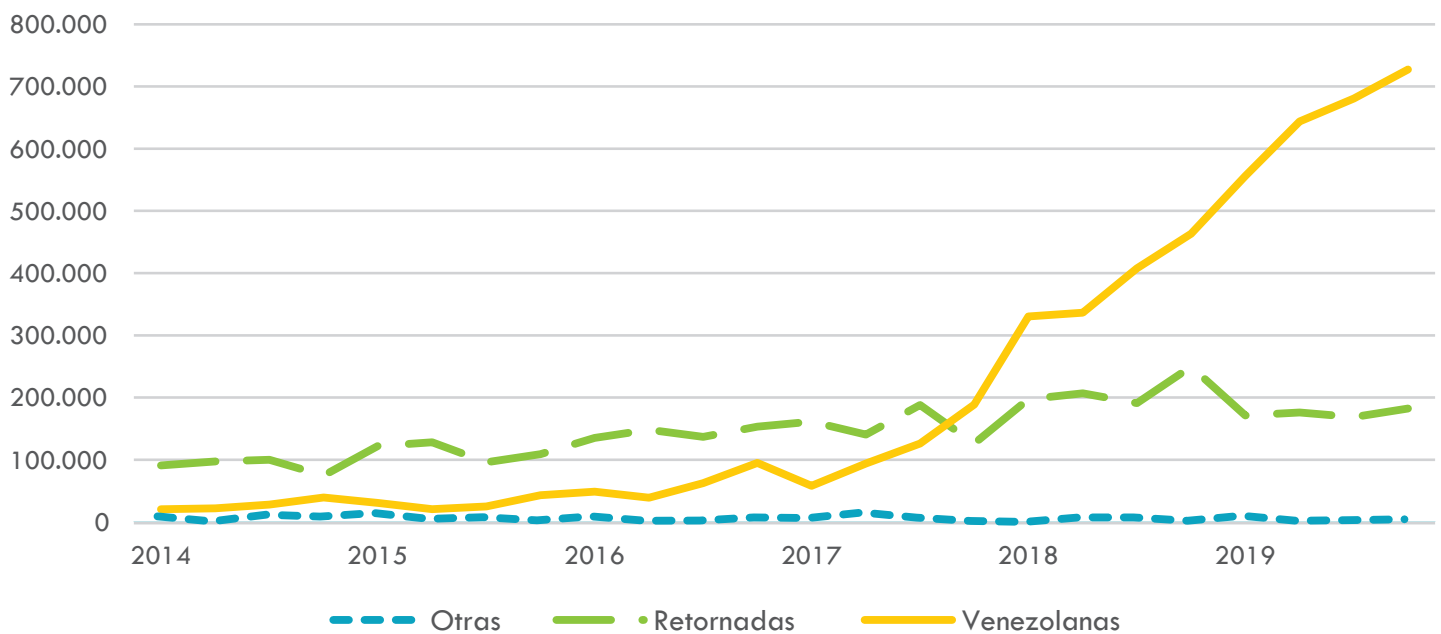

Fuente: elaboración propia con información de la GEIH (DANE, 2014; 2015; 2016a; 2017; 2018; 2019). 


\section{Marco analítico}

Este trabajo adopta diferentes enfoques teóricos que guían las hipótesis detrás de las cuatro preguntas que estructuran el análisis. El marco analítico incorpora teorías de la inserción laboral de inmigrantes, teorías de la participación laboral femenina y enfoques analíticos específicos, como la inserción laboral de inmigrantes forzados.

La primera hipótesis del estudio plantea que, frente a las mujeres locales, las inmigrantes en Colombia presentan indicadores laborales menos favorecedores. Dentro del análisis de la inserción laboral de los inmigrantes en los mercados de trabajo de destino, tres aproximaciones teóricas han marcado las principales pautas de estudio para este fenómeno: el enfoque del pluralismo y la asimilación cultural, la teoría del capital humano y el enfoque estructuralista (Caicedo, 2010). El primer enfoque plantea que los inmigrantes llegan a mercados jerarquizados, donde su éxito dependerá de la movilidad ascendente que tengan, la cual, a su vez, responderá a su nivel de aculturación, lo que significa que, si no se aculturan, pueden estancarse (Gordon, 1964).

La teoría del capital humano sostiene que el éxito en la inserción laboral del inmigrante depende de sus capacidades y cultura. Si no tienen un acervo importante de capital humano, sus posibilidades se reducen (Becker, 2009). Finalmente, la teoría estructuralista señala que el mercado de trabajo es un sistema dual, de mercados primarios y secundarios, donde los inmigrantes llegan a ocupar las plazas laborales que los locales no están dispuestos a tomar y donde las condiciones laborales son peores; lo anterior marca un panorama inicial de desventajas para los inmigrantes en los mercados de destino (Pioré, 1983; Caicedo, 2010). Para el caso de la inserción laboral de las inmigrantes venezolanas, la teoría estructuralista brinda un mejor bosquejo para validar la primera hipótesis.

La segunda hipótesis plantea que, dentro de los inmigrantes, son las venezolanas, como refugiadas, quienes presentan mayores desafíos en el mercado laboral. Además de las teorías generales de la inserción laboral de los inmigrantes, se ha encontrado que las condiciones de inserción y participación laboral no solo varían por la condición de migrante o nativo de un individuo, sino que el tipo de migración también tiene incidencia en los indicadores laborales, especialmente si se habla de una migración forzada (Becker y Ferrara, 2019). De acuerdo con Ruiz y Vargas-Silva (2018), las principales diferencias laborales entre inmigrantes forzados y otro tipo de inmigrantes pueden ser explicadas por las diferentes percepciones de seguridad en los lugares de destino, frente a los lugares de origen y cuánto se está dispuesto a renunciar y a pagar por ello. Es decir, para algunos inmigrantes la diferencia en las percepciones de seguridad (seguridad física, política, etc.) puede ser tan significativa que se decida migrar incluso esperando peores resultados laborales y asumiendo el costo de la migración a cualquier precio. Además, la inmigración forzada implica pérdidas en múltiples dimensiones que se traducen en retos adicionales para la inserción laboral en los lugares de destino. Por ello, es de esperarse que, dentro del estudio laboral de los fenómenos migratorios, los inmigrantes forzados sean quienes inicialmente muestren las mayores desventajas.

La tercera hipótesis que se plantea en esta investigación es que las diferencias en los resultados laborales de las inmigrantes venezolanas no son el resultado de sus características de capital humano, sino de una acumulación de desventajas por su condición. La experiencia laboral de un inmigrante, especialmente forzado, es diferente para hombres y para mujeres, así como sus estrategias para afrontar los retos del mercado (Calderón et al., 2011; Silva, 2012). La inserción y desempeño laboral de las mujeres migrantes está caracterizada por un trasvase de desigualdades de ocupaciones, condiciones e ingresos. En particular, la feminización en los flujos migratorios tiende a resultar en una transferencia de cargas reproductivas desde las mujeres nativas que tienen mayores oportunidades de inserción en los mercados locales, hacia las mujeres inmigrantes, aunque tengan similares niveles de formación, puesto que estas últimas ven sis- 
temáticamente vetadas sus oportunidades en los mercados receptores y requieren ingresos en el corto plazo para su subsistencia y la de sus familias (Parella, 2004).

Esta situación va de la mano con la inserción a trabajos menos cualificados y de menor calidad laboral, pues, como señalan Colectivo loé (2001) y Parella (2003), se ha encontrado que el nicho laboral para las mujeres inmigrantes se consolida en oportunidades alrededor de necesidades de apoyo en la esfera reproductiva, de cuidado, actividades poco cualificadas, caracterizadas por la precariedad, bajos salarios, invisibilidad, desregulación y desprestigio social como lo viven las trabajadoras sexuales; lo que resulta en una acumulación de desigualdades para estos colectivos en particular.

En esta línea de análisis, los determinantes laborales para el estudio de la inserción laboral de mujeres inmigrantes presentan particularidades que la teoría enfoca no solo en el capital humano, sino en los roles familiares y las características de los hogares. Algunos estudios encuentran como determinantes de la participación laboral femenina aspectos como los roles dentro del hogar, la presencia de hijos menores, el estado civil de la mujer o el tamaño del hogar (Oliveira y García, 1990; Mier-y-Terán, 1992; Rodríguez y Muñoz, 2018). Además, los procesos de inmigración traen consigo cambios en la estructura y organización de los hogares hacia hogares extensos, compuestos, ampliados, de corresidentes no emparentados; donde se suele propiciar la jefatura femenina, mayores posibilidades de empoderamiento mediante el efecto mediador del mercado laboral, mayor control de los recursos económicos y gastos del hogar, pero a su vez también mayores cargas frente a la participación en el mercado de trabajo (Ariza, 2017).

Finalmente, la cuarta hipótesis plantea que las inmigrantes con mayor tiempo de asentamiento tendrían mejores resultados laborales, incluso sobre algunas locales. El enfoque teórico de la asimilación señala que el tiempo de asentamiento en el lugar de destino es un factor determinante para el éxito en la inserción laboral de los inmigrantes, pues a través de la asimilación estructural se permite la movilidad ascendente desde la base de los mercados laborales jerarquizados, dado que los inmigrantes, a su llegada, suelen insertarse en los eslabones más bajos (Caicedo, 2010). Además, aunque tanto inmigrantes voluntarios como forzados se ven en la necesidad de pasar por un proceso de adaptación, existe evidencia que señala que los inmigrantes forzados presentan una adaptación más rápida, lo que significa que, aunque sus ingresos laborales sean inicialmente más bajos, estos tienden a mejorar más rápido frente a otros migrantes, lo que en parte se explica por una mayor inversión en capital humano en los lugares de destino, a raíz de las pérdidas materiales sufridas por el desplazamiento (Becker y Ferrara, 2019). Estos planteamientos resultan de gran relevancia al analizar la evolución en el tiempo de las condiciones de los inmigrantes forzados, pues se esperaría que su proceso de convergencia sea positivo y más acelerado frente a otros inmigrantes.

En este contexto, el trabajo busca dar respuesta a las preguntas planteadas bajo las hipótesis que la teoría y otros estudios han marcado, buscando ahondar en los temas de inserción migratoria con enfoque de género y visibilizar la existencia de desventajas acumuladas.

\section{Datos}

Para esta investigación se utilizó la Gran Encuesta Integrada de Hogares (GEIH) para los periodos 2014 a 2019, disponible a través del Departamento Administrativo Nacional de Estadística (DANE, 2014; 2015; 2016a; 2017; 2018; 2019), la cual proporciona información sobre el tamaño y estructura de la fuerza de trabajo de Colombia, así como datos sobre características sociodemográficas de la población. La GEIH es una encuesta transversal continua por muestreo, que recoge información mensual a nivel nacional y regional, tanto para áreas urbanas como para áreas rurales, con un error de muestreo registrado del $5 \%$ aproximadamente (DANE, 2016b). A partir de abril de 2013, la encuesta cuenta con un módulo de migración con información detallada, tal como el año de partida, la región de origen y la causa 
de la migración. Se integraron los módulos de características generales, ocupación y migración, lo que permitió obtener información relevante para una muestra de 555.208 mujeres en edad de trabajar, entre $15^{3}$ a $65^{4}$ años.

Para el desarrollo del análisis, fue necesaria la construcción de una clasificación de migrantes, así como indicadores laborales tales como:

* Tipo de migración: donde se clasificó a las mujeres en edad laboral de acuerdo con su experiencia migratoria (mujeres nacidas en Venezuela con migración en los 12 meses y 5 años previos a la encuesta; mujeres que migraron dentro de Colombia en los 12 meses y 5 años previos; mujeres colombianas que vivieron en Venezuela en los 12 meses o 5 años previos; y mujeres provenientes de cualquier otro país, ya sea en los 12 meses o los 5 años previos a la encuesta "otros migrantes") ${ }^{5}$. El grupo de referencia (o locales) es el conjunto de personas restantes, es decir, aquellas que no experimentaron migración, interna ni externa, en los 12 meses o 5 años previos a la encuesta.

* Empleo formal: con base en las investigaciones de Ferreira (2014) y en la metodología del DANE para la medición de la formalidad (DANE, 2009), se codificó la variable de formalidad a partir de dos características del empleo: i) se considera como formal a los trabajadores de empresas que cuentan con 5 o más empleados y ii) si es

3 De acuerdo con el Código de Infancia y Adolescencia, en su Artículo 35, se establece que, en Colombia, la edad mínima de admisión al trabajo es a los 15 años (Congreso de la República de Colombia, 2006).

4 Se tomó como referencia el tope de edad máximo utilizado por Calderón-Mejía e Ibáñez (2016) para el estudio de los efectos en el mercado laboral colombiano relacionados con la migración.

5 Este grupo corresponde en su mayoría a migrantes laborales que se insertan en puestos directivos o especializados, o migran por formación familiar. Su perfil es mucho más calificado que los demás grupos de migrantes (presentan mayores niveles promedio de escolaridad), y sus indicadores laborales son sustancialmente mejores, incluso frente a los colombianos (DANE, 2014; 2015; 2016a; 2017; 2018; 2019). un trabajador independiente o labora en el sector público. En contraparte, esta variable considera como informales a los trabajadores en empresas de menos de 5 personas, a los trabajadores domésticos, jornaleros, peones y patrones con menos de 5 personas empleadas.

* Empleo precario: se utilizó un índice ya aplicado para Colombia por Farné et al. (2013), desarrollado por la oficina de la OIT y bajo el concepto de trabajo decente (Ojeda-Pérez et al., 2019), el cual considera cuatro elementos ponderados por tipo de trabajador: para los asalariados se compone de $40 \%$ del ingreso, $25 \%$ del contrato, $25 \%$ de seguridad social y $10 \%$ de las horas semanales; para los independientes, el 50\% corresponde al ingreso, $35 \%$ a la seguridad social y el $15 \%$ a las horas semanales. ${ }^{6}$ Adicionalmente, se invierte la escala para contar un análisis más claro, donde 100 es un trabajo altamente precario y 0 , un trabajo decente.

* Dependencia económica: esta variable muestra el porcentaje de personas al interior de la familia que dependen del ingreso de los trabajadores, donde el $0 \%$ muestra que ningún miembro depende de alguien más y todos están trabajando, mientras que el $100 \%$ considera que hay una dependencia total (ninguno trabaja).

La modelización implica el uso de variables de control para los análisis. En la Tabla 1 se presentan estadísticos descriptivos de algunas de estas variables y se observa que, en promedio, las venezolanas trabajan más horas a la semana por un ingreso mensual menor, son más jóvenes frente a los demás grupos, tienen mayor registro de escolaridad, mínima participación gremial, niveles de subempleo mayores, menos experiencia, menos registro de contratación y sus indicadores de calidad laboral (formalidad y precariedad) son los más bajos. Igualmente, presentan un registro menor de jefatura del hogar, tamaño de familias más grandes y mayor cantidad de infantes menores de 5 años en sus hogares, lo que da cuenta, en un primer momento, de sus retos en el mercado laboral colombiano.

6 Los elementos que constituyen el indicador, así como la definición de los criterios aplicados para su construcción, pueden revisarse en Farné et al. (2013, p. 19). 
Sociedad y Economía N 44 (Sep - dic 2021) / e-ISSN: 2389-9050 / e10410743

Inserción laboral de inmigrantes venezolanas, 2014-2019: ¿acumulación de desventajas?

Tabla 1. Comparación entre los valores promedio de los indicadores, por tipo de características, para los diferentes grupos de migrantes

\begin{tabular}{|c|c|c|c|c|c|}
\hline Característica & Locales & Internas & Retornadas & Venezolanas & Otras \\
\hline Horas trabajadas al mes & 173,34 & 180,16 & 174,98 & 191,57 & 173,81 \\
\hline Ingresos mensuales* & 852.017 & 886.308 & 890.309 & 610.531 & $2^{\prime} 158.250$ \\
\hline Ingreso por hora & $5.086,92$ & $5.152,25$ & $5.417,74$ & $3.315,35$ & $14.692,65$ \\
\hline Porcentaje de ocupadas & 54,85 & 50,43 & 55,53 & 53,51 & 50,81 \\
\hline Precariedad & 58,45 & 61,52 & 65,91 & 83,14 & 53,97 \\
\hline Edad & 39,52 & 33,02 & 38,12 & 31,67 & 33,29 \\
\hline Escolaridad & 10,69 & 11,01 & 10,67 & 11,15 & 14,2 \\
\hline Tasa de dependencia & 0,52 & 0,57 & 0,52 & 0,56 & 0,6 \\
\hline Casada & 0,5 & 0,49 & 0,47 & 0,58 & 0,63 \\
\hline Formalidad & 0,37 & 0,38 & 0,27 & 0,19 & 0,41 \\
\hline Experiencia & 28,83 & 22,01 & 27,45 & 20,52 & 19,04 \\
\hline Tiene contrato & 0,56 & 0,63 & 0,49 & 0,49 & 0,52 \\
\hline Hijos menores de 5 años & 0,35 & 0,41 & 0,45 & 0,66 & 0,34 \\
\hline Ingreso sin mujeres & 768.613 & 797.686 & 813.401 & 827.153 & $1 ' 640.594$ \\
\hline Jefa del hogar & 0,34 & 0,35 & 0,33 & 0,26 & 0,43 \\
\hline Tamaño de familia & 3,97 & 3,47 & 4,14 & 4,3 & 2,54 \\
\hline Subempleo & 0,38 & 0,43 & 0,45 & 0,53 & 0,42 \\
\hline Pertenencia a gremios & 0,04 & 0,03 & 0,01 & 0,01 & 0,02 \\
\hline Trabajo ocasional & 0,88 & 0,84 & 0,85 & 0,84 & 0,92 \\
\hline
\end{tabular}

Nota: el tipo de cambio de un dólar equivale aproximadamente a 3.730 COP (a septiembre de 2020).

Fuente: elaboración propia con base en información trimestral de la GEIH (DANE, 2014; 2015; 2016a; 2017; 2018; 2019).

\section{Metodología}

El análisis se concentra en cuatro indicadores de la situación laboral de las migrantes (variables dependientes): i) diferencias en la probabilidad de estar empleadas, ii) diferencias de ingreso laboral por hora trabajada, iii) probabilidad de formalidad en el empleo y iv) precariedad en su participación laboral (estas dos últimas estimaciones se realizan como un proxi para la calidad de la inserción laboral). Los cuatro ejercicios corresponden a las cuatro preguntas de investigación y se desarrollan a través de 16 ejercicios multivariados de regresión.

Para la primera pregunta, la evaluación de las diferencias en los indicadores laborales para cada grupo de migrantes frente a las mujeres sin experiencia migratoria (locales), se toma como grupo de referencia a las mujeres sin experiencia migratoria reciente (o locales) bajo la identificación del siguiente modelo econométrico probit:
Donde $y_{i}$ es el resultado laboral de interés, $M I_{i}$ es una variable dicotómica para migración interna, $M R_{i}$ es la variable dicotómica para la migración de retorno desde Venezuela, $M V_{i}$ es la variable dicotómica para la migración de venezolanas, $O E_{i}$ es una variable dicotómica para migración

$y_{i}=\alpha_{0}+\alpha_{1} M I_{i}+\alpha_{2} M R_{i}+\alpha_{3} M V_{i}+\alpha_{4} O E_{i}+\theta X_{i}+\varepsilon_{i}$

externa desde otros destinos diferentes a Venezuela, $X_{i}$ son variables de control individual que varían de acuerdo a la variable dependiente a estimar y $\varepsilon_{i}$ es el término de error.

Para dar respuesta a la segunda pregunta, diferencias entre grupos de migrantes, el grupo de referencia son las migrantes venezolanas y los indicadores laborales se analizan a través del modelo:

$y_{i}=\alpha_{0}+\alpha_{1} M I_{i}+\alpha_{2} M R_{i}+\alpha_{3} O E_{i}+\theta X_{i}+\varepsilon_{i}$ 
Donde $y_{i}$ es el resultado laboral de interés, $M I_{i}$ es una variable dicotómica para migración interna, $M R_{i}$ es la variable dicotómica para la migración de retorno desde Venezuela, $O E_{i}$ es una dicotómica para migración externa desde otros destinos diferentes a Venezuela, $X_{i}$ son variables de control individual que varían de acuerdo a la variable dependiente a estimar y $\varepsilon_{i}$ es el término de error.

Para la tercera pregunta se explora la incidencia de algunas variables individuales sobre los indicadores de las migrantes venezolanas recientes y se analizan estas diferencias a través de una comparación directa con los resultados para las mujeres sin experiencia migratoria reciente o locales. El modelo utilizado para los dos grupos de comparación es:

$y_{i}=\alpha_{0}+\alpha_{1} C H_{i}+\alpha_{2} V H_{i}+\alpha_{3} S E_{i}+\alpha_{4} X_{i}+\varepsilon_{i}$

Donde $y_{i}$ es el resultado laboral de interés. El resto son variables independientes para la estimación de cada resultado laboral entre las que se encuentran variables de capital humano $\mathrm{CH}_{i}$ como la educación medida en años, nivel educativo medido en ciclo escolar culminado, la experiencia y la edad; algunas variables de hogar $\mathrm{VH}_{i}$ como la cantidad de niños menores de 5 años, el tamaño del hogar, la dependencia económica, el estado civil casada o en unión conyugal y área de ubicación del hogar; algunas variables de índole socioeconómico $S E_{i}$ como la existencia de contrato laboral, afiliación a gremios, tamaño de la empresa, rama del sector económico; algunas variables de control $X_{i}$ como el $a \tilde{n} o$ y el departamento y $\varepsilon_{i}$ como el término de error.

Por último, para la cuarta pregunta del estudio, aunque se reconocen las limitaciones de estimar la convergencia en $\mathrm{si}^{7}$, se realiza

7 No se cuenta con una base de datos panel, es decir, no se está analizando al mismo individuo en la línea de tiempo. Sin embargo, el ejercicio busca hacer una estimación de los cambios que pueden existir en los indicadores laborales en el tiempo para los diferentes grupos analizados a través de la información de la encuesta transversal disponible, lo que permite tener una aproximación al fenómeno. un ejercicio comparativo para explorar la posible tendencia en el mediano plazo entre los indicadores laborales para las migrantes recientes (mujeres que migraron en los últimos 12 meses) y para las migrantes intermedias (mujeres que migraron hace 5 años, pero que no migraron en los 12 meses previos). Algunos estudios han encontrado que, en los primeros años, la experiencia de la migración que tiende a ser más difícil para los migrantes es la inserción, especialmente para los migrantes forzados, pero con el proceso de asimilación en la comunidad de destino, las diferencias en resultados laborales tienden a reducirse en los horizontes temporales de estas poblaciones (Ruiz y Vargas-Silva, 2017; Morales, 2018; Cortés, 2004).

Para ello, se tomaron las regresiones del primer ejercicio de análisis de indicadores laborales (con mujeres locales como grupo de referencia) y se incluyeron los grupos de migrantes de temporalidad intermedia para observar las diferencias entre las poblaciones que migraron hace menos de 12 meses. En esta etapa, el análisis incluye los grupos de migrantes diferenciados por temporalidad, a partir de las locales como grupo de referencia, bajo la especificación del siguiente modelo para cada uno de los cuatro escenarios laborales estudiados:

$y_{i}=\alpha_{0}+\alpha_{1} M I R_{i}+\alpha_{2} M R R_{i}+\alpha_{3} M V R_{i}+\alpha_{1} M I I_{i}+\alpha_{2} M R I_{i}+$ $\alpha_{3} M V I_{i}+\alpha_{4} O E_{i}+\theta X_{i}+\varepsilon_{i}$

Donde $y_{i}$ es el resultado laboral de interés, $M I R_{i}$ es una variable dicotómica para migración interna reciente (en los últimos 12 meses), $M R R_{i}$ es la variable dicotómica para la migración de retorno reciente desde Venezuela, $M V R_{i}$ es la variable dicotómica para la migración de venezolanas reciente, $M I_{i}$ es una variable dicotómica para migración interna intermedia (en más de 12 meses, pero en menos de 5 años), $M R I_{i}$ es la variable dicotómica para la migración de retorno intermedia desde Venezuela, $\mathbf{M V I}_{i}$ es la variable dicotómica para la migración de venezolanas intermedia, $O E_{i}$ es una dicotómica para migración externa desde otros destinos diferentes a Venezuela, $X_{i}$ son variables de control individual que varían de acuerdo a la variable dependiente a estimar y $\varepsilon_{i}$ es el término de error. 


\section{Resultados}

Los resultados, en línea con cada una de las hipótesis planteadas, se presentan en cuatro segmentos, de acuerdo a las diferencias de los indicadores laborales entre grupos de estudio.

\subsection{Diferencias entre mujeres locales y grupos de migrantes}

La Tabla 2 presenta los resultados del comparativo de los indicadores laborales de probabilidad de ocupación, ingreso por hora, probabilidad de formalidad y nivel de precariedad de los grupos de migrantes internas, migrantes retornadas, migrantes venezolanas y otras migrantes internacionales ${ }^{8}$, tomando como referencia para el análisis a las mujeres sin experiencia migratoria reciente o locales.

Tabla 2. Comparativo de indicadores por tipo de migración, en relación con las locales

\begin{tabular}{|c|c|c|c|c|}
\hline \multirow{2}{*}{ Tipo de migrante } & \multicolumn{4}{|c|}{ Mujeres de referencia: locales } \\
\hline & Ocupación/1 & Ingreso por hr/ $/^{2}$ & Formalidad/ ${ }^{3}$ & Precariedad $/{ }^{4}$ \\
\hline \multirow{2}{*}{ Internas } & $-0,0065 * * *$ & $0,0655^{* * *}$ & $-0,0325^{* * *}$ & $3,1342 * * *$ \\
\hline & $(0,0021)$ & 0,0046 & 0,0019 & 0,1586 \\
\hline \multirow{2}{*}{ Retornadas } & $-0,0042$ & $0,0276^{*}$ & $-0,0491 * * *$ & $2,9641 * * *$ \\
\hline & $(0,0067)$ & 0,0154 & 0,0067 & 0,4486 \\
\hline \multirow{2}{*}{ Venezolanas } & $-0,0435^{* * *}$ & $-0,2464 * * *$ & $-0,1327^{* * *}$ & $17,9686 * * *$ \\
\hline & $(0,0053)$ & 0,0138 & 0,0059 & 0,3249 \\
\hline \multirow{2}{*}{ Otras } & $-0,0318$ & $0,5543 * * *$ & $-0,0327$ & $4,1520^{*}$ \\
\hline & $(0,0346)$ & 0,0998 & 0,0319 & 4,257 \\
\hline $\mathrm{R}^{2}$ & --- & 0,3635 & --- & 0,4274 \\
\hline Pseudo $\mathrm{R}^{2}$ & 0,385 & --- & 0,531 & --- \\
\hline
\end{tabular}

Notas:// Considera la edad, la edad al cuadrado, años de educación, si es casada/vive en unión, el número de niños menores de 5 años en el hogar, el logaritmo del Ingreso familiar sin el ingreso de la mujer, tamaño del hogar, nivel de dependencia del hogar, si es jefa del hogar y variables de control como el año, el departamento y el área urbana o rural.

12 Considera la edad, nivel educativo, dependencia del hogar, si es casada, área donde vive, si es formal, el departamento y año.

${ }^{13}$ Considera los años de educación, la experiencia, la experiencia al cuadrado, si cuenta con contrato, el logaritmo del ingreso, el tamaño de la familia, cuántos hijos menores de 5 años tienen, la rama de actividad económica y el año.

${ }^{14}$ Considera si se encuentra en subempleo, tamaño de la familia, tamaño de la empresa, rama de actividad económica, si pertenece a un gremio y los años de educación.

*** es significativo al $1 \%$, ** es significativo al $5 \%$ y $*$ es significativo al $10 \%$.

Fuente: cálculos del autor utilizando la información trimestral de la GEIH (DANE, 2014; 2015; 2016a; 2017; 2018; 2019).

Los resultados muestran que la probabilidad de ocupación para las migrantes internas y las migrantes venezolanas es menor a la probabilidad de ocupación que presentan las mujeres locales, pero en magnitudes muy pequeñas. Para las migrantes retornadas no se presentó diferencia estadística en su probabilidad de ocupación frente a las mujeres sin experiencia migratoria reciente.
Estos datos no resultan del todo sorprendentes ya que muchos de los estudios que analizan el comportamiento laboral de los inmigrantes refugiados se han encontrado con estas diferencias a favor de la población sin experiencia migratoria. Tal es el caso de los estudios llevados a cabo por Ruiz y Vargas-Silva (2017; 2018), donde se encontró que para los mi-

8 Aunque este grupo de migrantes no es objeto de este estudio y representa tan solo el 0,4\% de la muestra, son parte de la población inmigrante de la encuesta y se dejan como control para la estimación de los indicadores. 
grantes refugiados en $\mathrm{RU}$ la diferencia en las probabilidades de ocupación respecto a los no migrantes, está entre 10 y $19 \%$. Para Dustman et al. (2017) las diferencias en empleabilidad entre refugiados y migrantes económicos en Europa se encuentran cerca del $10 \%$. Igualmente, Deryugina et al. (2018), en su estudio de los impactos económicos del huracán Katrina en EE. UU., evidencia que hay diferencias en la ocupación a favor de los locales frente a los migrantes forzados por este suceso en el corto plazo, pero con una recuperación rápida en el mediano.

Por otro lado, la baja magnitud de la diferencia también se explica por las altas necesidades de ocupación que presentan los migrantes refugiados al llegar a sus lugares de destino, los cuales presentarían mayor disponibilidad a emplearse sin restricciones, así como a la creación progresiva en el tiempo de redes con otros migrantes refugiados, especialmente si estos son empleadores, pues tienden a dar trabajo con mayor facilidad a sus connacionales (Dagnelie et al., 2018).

Respecto a los resultados del indicador laboral "ingresos por hora", la estimación sugiere que las migrantes internas presentan una diferencia de alrededor de un 6\% por encima de los ingresos por hora de las locales, así como las migrantes retornadas, las cuales también presentan una diferencia positiva de un $2 \%$ frente al mismo grupo de referencia. Estas cifras concuerdan con los valores esperados, ya que la mayoría de las migrantes internas están conformadas por mujeres que han migrado por razones de trabajo o de familia, lo que facilita su colocación laboral y condiciones dentro de sus posibilidades; mientras que los migrantes retornados tienden a regresar a sus lugares de origen como trabajadores independientes a establecer sus propios negocios (Hausmann y Nedelkoska, 2018).

Sin embargo, dentro de todos los grupos de migrantes, las venezolanas son las únicas con diferencias negativas, ya que los resultados sugieren que existiría una diferencia en los ingresos por hora entre locales y venezolanas de cerca de un $25 \%$ menos para estas últimas.
Dustmann y Schmidth (2000) encontraron estos mismos resultados para las diferencias de ingresos entre mujeres migrantes forzadas y no migrantes en Alemania, tanto de trabajos de tiempo completo como de tiempo parcial, concluyendo que estas diferencias respondían principalmente a sus discrepancias en cuanto a capital humano.

Estos resultados también dan cuenta de las diferencias existentes dentro de las variables que componen el indicador de ingresos por hora, donde se evidencia que las migrantes venezolanas estarían presentando una mayor necesidad de horas de trabajo, pues en promedio laboran cerca de 5 horas más a la semana que las locales, pero con un salario $30 \%$ menor. Los efectos combinados de salarios más bajos y mayores horas trabajadas a la semana explicarían el margen de desigualdad de ingresos por hora entre las migrantes venezolanas y las locales, pero evidenciando a la vez que la mayor brecha se encuentra en los ingresos laborales.

Los indicadores de calidad laboral evidencian la marcada diferencia entre migrantes locales. Las migrantes de las tres categorías de interés presentan menores probabilidades de pertenecer al sector formal y mayor precariedad. Evidencia empírica, presentada por Bratsberg et al. (2018), muestra que los inmigrantes refugiados suelen estar sobrerrepresentados en empresas precarias con alta probabilidad de reducción de personal o cierre, y que, frente a trabajadores nativos, son ellos los que suelen asumir las peores consecuencias. Igualmente, Morales (2016), en su análisis de corredores regionales migratorios en Latinoamérica, concluye que actualmente los migrantes deben enfrentarse a abusos de derechos laborales, condiciones precarias de trabajo, trato xenofóbico y restricciones a su reunificación familiar, especialmente si su condición es de refugiados.

\subsection{Diferencias entre grupos de migrantes}

La Tabla 3 contiene una comparación de los indicadores laborales exclusivamente entre los grupos de migrantes, donde ahora el grupo de referencia corresponde a las migrantes 
venezolanas. Los datos indican que cualquier grupo de inmigrantes presenta mejores resultados en cada uno de los indicadores laborales frente a las inmigrantes venezolanas -en proporciones similares entre ellos- o, lo que es lo mismo, comprueba que el colectivo de mujeres venezolanas son las que mayores desventajas presentan en el mercado laboral colombiano, tanto frente a mujeres locales, como frente a otras inmigrantes.

Tabla 3. Comparativo de indicadores, por tipo de migración, en relación a las venezolanas

\begin{tabular}{ccccc}
\multirow{2}{*}{ Tipo de migrante } & \multicolumn{4}{c}{ Mujeres de referencia: venezolanas } \\
\cline { 2 - 5 } & Ocupación $/{ }^{1}$ & Ingreso por hr/ ${ }^{2}$ & ${\text { Formalidad } /{ }^{3}}^{\text {Precariedad } / 4}$ \\
\hline \multirow{2}{*}{ Internas } & $0,0341^{* * *}$ & $0,3085^{* * *}$ & $0,1187^{* * *}$ & $-14,895^{* * *}$ \\
& $(0,0055)$ & 0,0153 & $(0,0065)$ & 0,2883 \\
\hline \multirow{2}{*}{ Retornadas } & $0,0493^{* * *}$ & $0,2774^{* * *}$ & $0,1039^{* * *}$ & $-15,052^{* * *}$ \\
& $(0,0084)$ & 0,0211 & $(0,0096)$ & 0,4058 \\
\hline \multirow{2}{*}{ Otras } & 0,0295 & $0,8095^{* * *}$ & $0,1186^{* * *}$ & $-14,867^{* * *}$ \\
\hline $\mathrm{R}^{2}$ & $(0,0339)$ & 0,1013 & $(0,0369)$ & 2,2582 \\
\hline Pseudo $\mathrm{R}^{2}$ & $-\cdots$ & 0,317 & $-\cdots$ & 0,5505 \\
\hline
\end{tabular}

Nota: $* * *$ es significativo al $1 \%$, ** es significativo al $5 \%$ y es significativo al $10 \%$.

Fuente: cálculos del autor utilizando la información trimestral de la GEIH (DANE, 2014; 2015; 2016a; 2017; 2018; 2019).

Respecto a la probabilidad de ocupación, los otros grupos de migrantes presentan diferencias positivas de entre $3 \%$ y $5 \%$. Es decir, tienen mayores niveles de probabilidad de ocuparse que las venezolanas, presentan ingresos por hora en alrededor de $30 \%$ más (y hasta $80 \%$ más para el caso de otras migrantes internacionales), niveles de probabilidad de formalidad superiores en alrededor de $11 \%$ y diferencias en niveles de precariedad de cerca de $15 \%$ menos que las migrantes de referencia.

\subsection{Determinantes laborales entre mujeres locales y migrantes venezolanas}

La hipótesis tres sostiene que las diferencias en los resultados de las migrantes venezolanas no estarían concentradas en su capital humano. La Figura 2 contiene las diferencias en los resultados de los determinantes para cada indicador laboral y se presentan para el grupo de las mujeres locales (como grupo de referencia) y para las inmigrantes venezolanas.

En términos generales, los resultados de las estimaciones sugieren que variables ampliamen- te reconocidas por la teoría económica como determinantes laborales de capital humano, en este caso años de educación y nivel educativo, y aplicables en mujeres jóvenes colombianas (Castillo y García, 2019), resultan tener mayor peso en los indicadores laborales de las mujeres locales que para las mujeres migrantes, aunque estas últimas presenten en promedio mayor educación.

Además, los modelos permiten observar que las variables de hogar presentan mayor peso para el grupo de migrantes venezolanas, a excepción de la variable tamaño del hogar, hecho que puede ser explicado por los cambios demográficos en la recomposición de sus hogares a unidades compuestas, extensas, ampliadas o de corresidentes no emparentados que pueden alterar la definición de tamaño del hogar para este colectivo (Ariza, 2017).

\subsection{Convergencia de indicadores laborales}

Finalmente, la última pregunta abarca la posible convergencia de los indicadores a lo largo del tiempo. La Figura 3 muestra los resultados de la estimación de la ecuación (4) para 
Sociedad y Economía N 44 (Sep - dic 2021) / e-ISSN: 2389-9050 / e 10410743

María Luz Moyano-Buitrago

Figura 2. Determinantes de características laborales. Locales vs. Venezolanas

0,0
0,06
0,04
0,0
$-0,0$
$-0,0$
$-0,06$
$-0,0$

0,1

Probabilidad de ocupación. Locales vs. Venezolanas

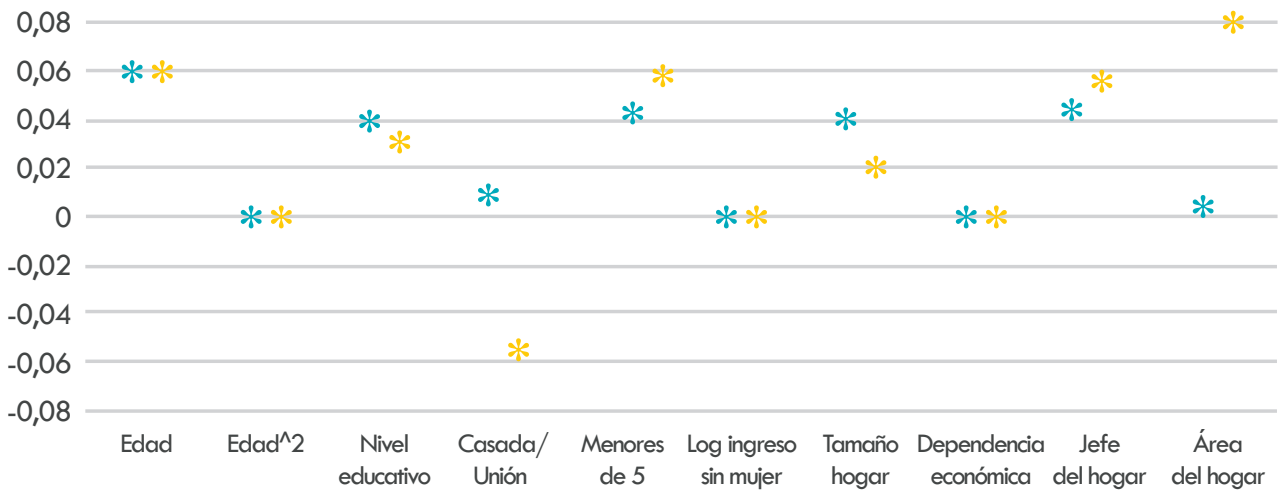

Ingreso por hora. Locales vs. Venezolanas

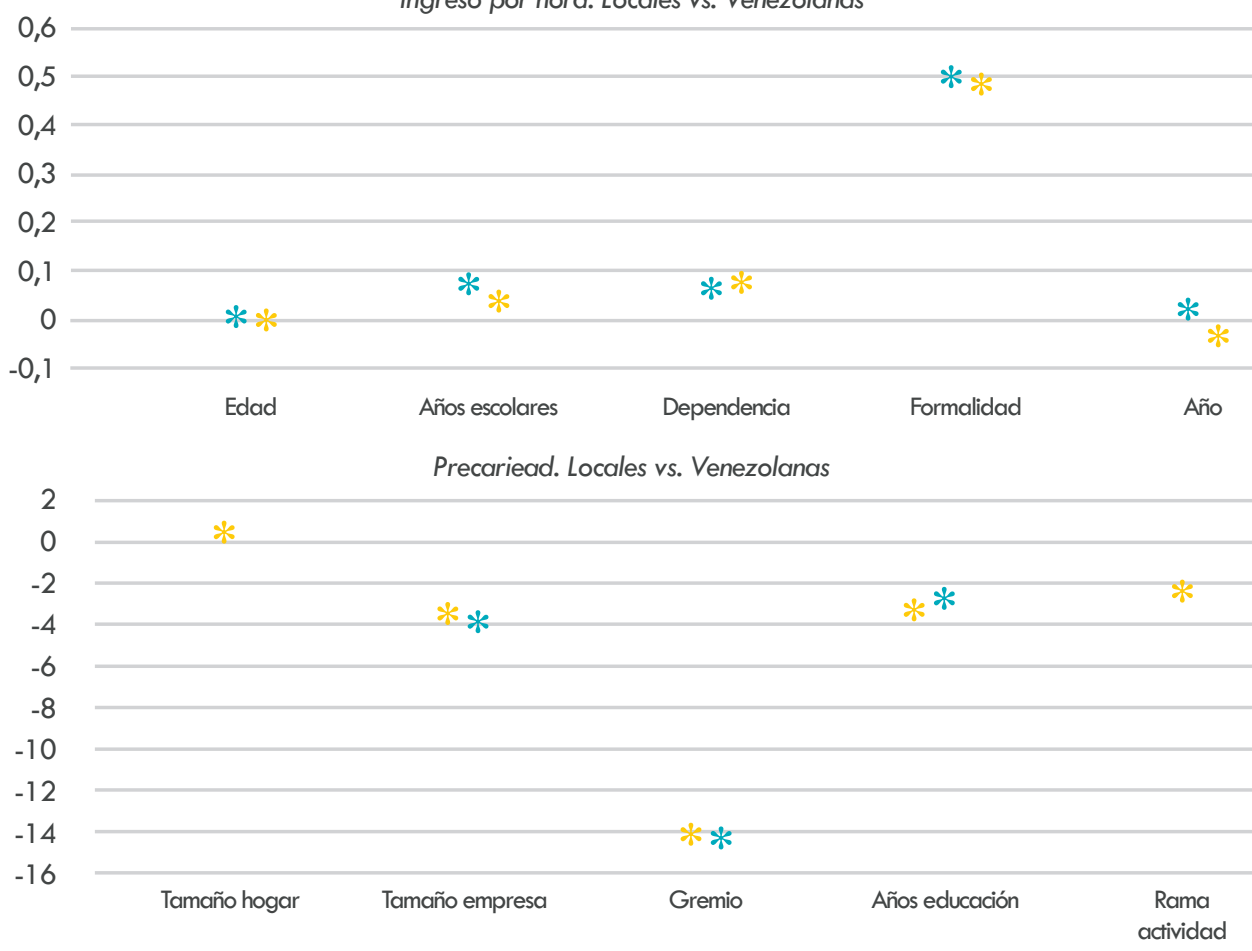

* Locales

* Venezolanas

* Locales

* Venezolanas

Probabilidad de formalidad. Locales vs. Venezolanas

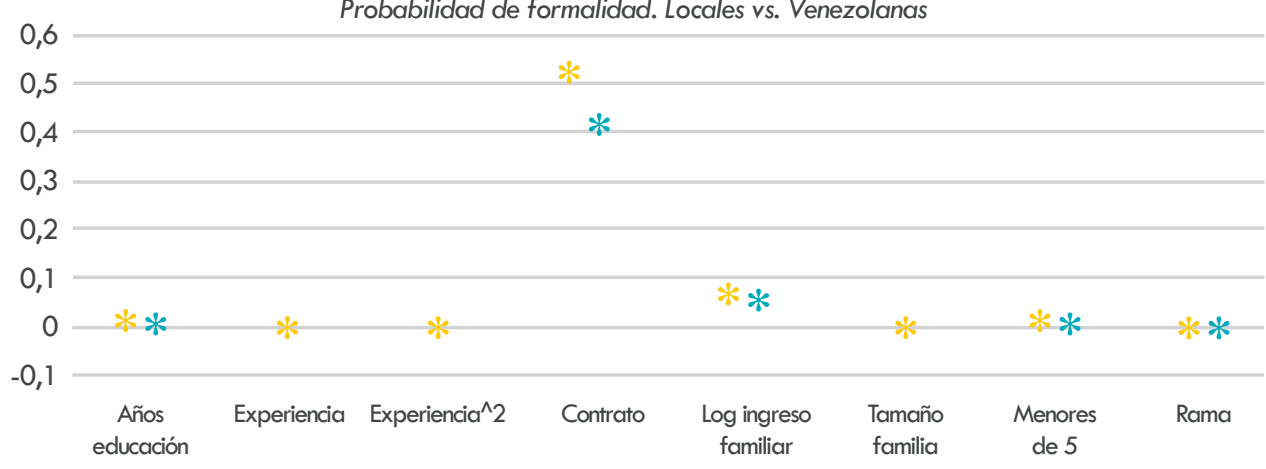

* Locales

* Venezolanas

Fuente: cálculos propios con información trimestral de la GEIH (DANE, 2014; 2015; 2016a; 2017; 2018; 2019). 
Figura 3. Convergencia de los indicadores laborales por momento de la migración y tipo de migrante

Diferencias en probabilidad de ocupación (\%)

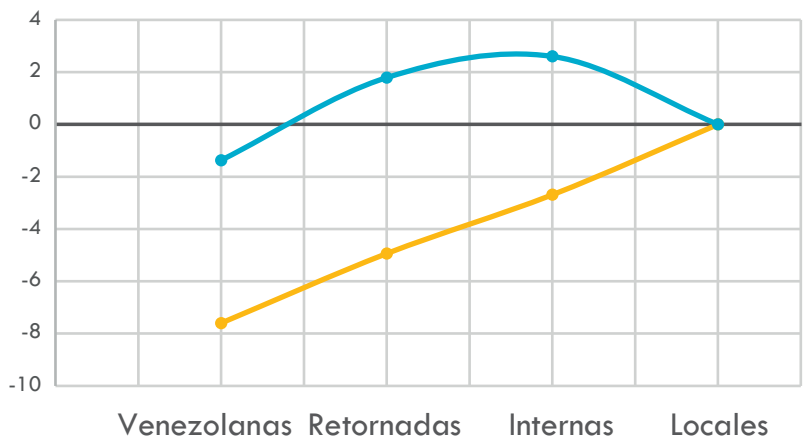

Diferencias en probabilidad de formalidad (\%)

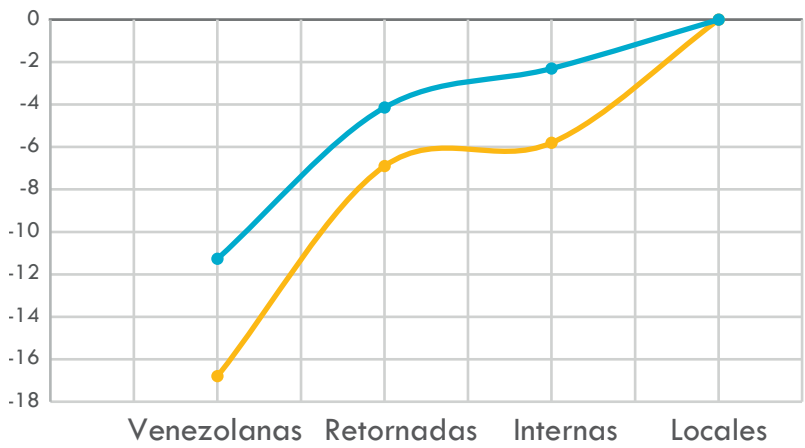

Diferencias en Ingresos por hora (\%)

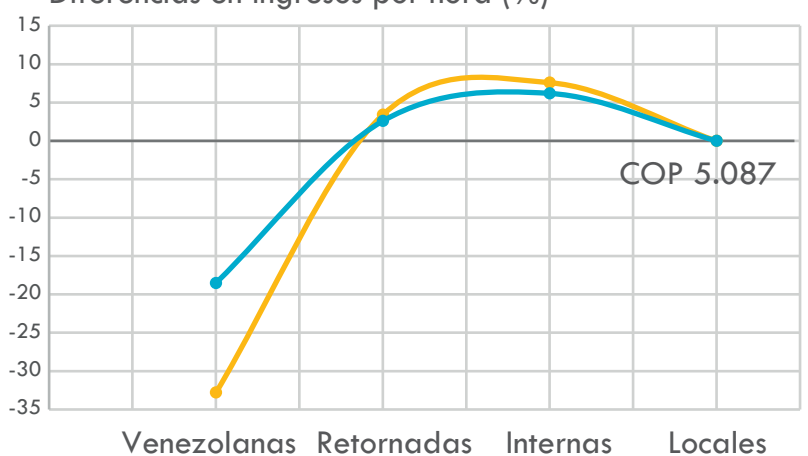

Diferencias en nivel de precariedad

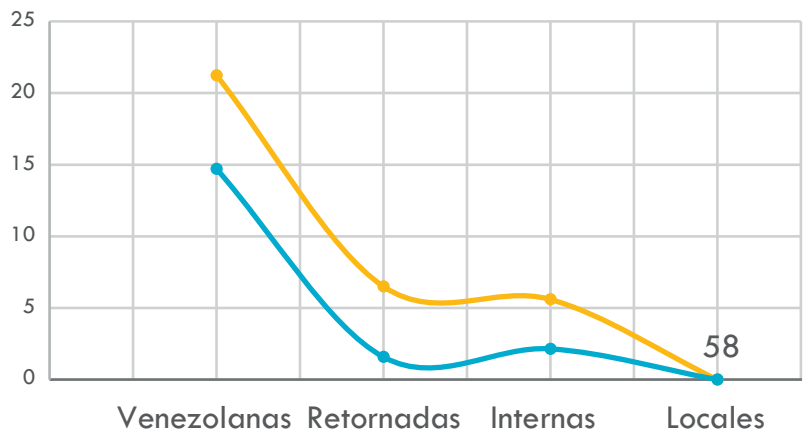

-12 Meses $\rightarrow 5$ Años

Fuente: cálculos propios con información trimestral de la GEIH (DANE, 2014; 2015; 2016a; 2017; 2018; 2019).

cada indicador a analizar dentro de los grupos de inmigrantes, tomando como referencia a las mujeres locales, pero diferenciando el periodo del desplazamiento entre migración reciente (si esta ocurrió en los 12 meses previos a la encuesta), y migración intermedia (si esta sucedió dentro de los 5 años previos, pero a su vez no ha existido migración en los últimos 12 meses). La línea 0 representa los resultados para las mujeres locales como grupo de referencia.

Los resultados sugieren que existiría una convergencia de los grupos de inmigrantes analizados en los indicadores laborales hacia los niveles de las mujeres locales a medida que el tiempo de asentamiento en el lugar de destino es mayor, así como diferencias en los resultados de cada uno de los indicadores que responderían directamente al tipo de migrante (si es interno, retornado o refugiado).
En términos generales, la migración reciente implica mayores desafíos para las migrantes frente a las mujeres locales y el incremento en la temporalidad en los lugares de destino mitigaría las diferencias laborales entre migrantes y no migrantes, especialmente para las inmigrantes refugiadas. Una explicación a ello se encuentra en que el proceso de asimilación o adaptación a los lugares de destino implican sustanciales desventajas iniciales, especialmente si la migración es forzada, pero a medida que pasa el tiempo, la inversión en capital tiende a incrementar dentro de los migrantes y sus redes sociales empiezan a consolidarse por el proceso de asimilación, lo que les permite obtener retornos a sus inversiones y reducir las diferencias frente a los locales (Becker y Ferrara, 2019; Cortés, 2004; Ruiz y VargasSilva, 2018). 


\section{Conclusiones}

Este trabajo presenta un primer acercamiento de carácter explicativo a la situación de vulnerabilidad que viven las mujeres inmigrantes venezolanas en Colombia. De esta manera, a partir de un marco analítico de inserción laboral-migrante, se aportan elementos para la discusión sobre la inclusión precaria de las migrantes venezolanas dada su condición de mujeres y migrantes forzadas en un mercado laboral colombiano ya de por sí envuelto en una matriz de desigualdades.

Los resultados de este análisis nos permiten aceptar la hipótesis general de que el colectivo de mujeres venezolanas presenta una mayor desventaja y vulnerabilidad laboral frente a las mujeres locales o sin experiencia migratoria, e incluso frente a otros grupos de migrantes, como las migrantes internas o las migrantes retornadas. En particular, se pudo determinar que las migrantes venezolanas presentan una menor probabilidad de ocupación frente a las mujeres locales, ingresos por hora sustancialmente más bajos, mayores niveles de precariedad laboral y menos probabilidades de trabajar en el sector formal; con lo que se corrobora lo planteado por las teorías económicas de la inmigración. Además, frente a los grupos de otros inmigrantes, sus indicadores laborales señalan que son el grupo con mayores desventajas, pues los demás inmigrantes presentan mayores probabilidades de ocupación, mayores niveles de ingresos por hora, mayores probabilidades de pertenecer al sector formal y menores niveles de precariedad.

Respecto a los determinantes de sus indicadores laborales, se evidenció que las variables de capital humano como años de educación, nivel educativo o experiencia, resultaron tener un mayor efecto en los indicadores laborales de las locales que de las migrantes venezolanas, aunque estas en promedio tuvieran indicadores de escolaridad más altos, lo que evidencia que la teoría del capital humano para los primeros momentos de la inserción laboral de las mi- grantes venezolanas no explica su desempeño. Sin embargo, las variables de hogar resultaron tener un mayor efecto en este grupo a excepción de la variable tamaño del hogar, la cual resultó ser no significativa en todos los modelos planteados. Como señala la teoría de la migración, hogares y familia; la composición, estructura y cambios familiares en los grupos migrantes pueden resultar ser de gran significancia para la determinación de sus condiciones laborales en los lugares de destino, por lo que los resultados de esta investigación sugieren que es importante profundizar en el estudio de las características de los hogares venezolanos.

También el estudio permitió observar indicios de convergencia a lo largo del tiempo en los indicadores laborales de las poblaciones migrantes. Como ya la teoría económica de la migración lo había sugerido, las poblaciones migrantes tienden a mejorar sus condiciones laborales en los lugares de destino gracias a la asimilación en el nuevo mercado y a la creación de redes. Los datos, aunque no suficientes para la evaluación de una temporalidad más amplia, permitieron observar que, en un mediado plazo, los migrantes venezolanos no son la excepción. Sin embargo, frente a los demás grupos de migrantes, su convergencia sigue siendo la más aletargada y sus resultados los más alejados a las condiciones de las locales.

Como evidenciaron los resultados, el género o el estatus migratorio en el mercado laboral colombiano, no asigna las mismas desventajas y de la misma manera a los participantes de un mercado laboral. Las mujeres venezolanas en el mercado de trabajo colombiano experimentan desafíos que no enfrentan otro tipo de inmigrantes en el mismo mercado, debido a las condiciones en las que se dio la inmigración y a los roles de género. Las diversas características y lugares sociales que dan lugar a interacciones binarias de desventajas son solo el primer indicador para evidenciar la existencia de interseccionalidad y la necesidad de estudios bajo este enfoque que capturen la complejidad de estas relaciones y formulen 
soluciones más precisas a estas problemáticas.

Además, para futuros estudios, y teniendo en cuenta que este trabajo es el inicio de una agenda de investigación, se reconoce la importancia de abordar el análisis de otras complejidades de los mercados laborales para los diversos tipos de poblaciones, como las características de los nichos laborales en los cuales se están insertando, el análisis de la internacionalización de los trabajos domésticos y de cuidado, así como la relación de estas características de ocupación con los diferenciales salariales entre grupos demográficos. Además, se recomienda abordar evaluaciones en cuanto a los efectos de las medidas gubernamentales como la TMF o el PEP en la inserción y desempeño laboral de los inmigrantes venezolanos en Colombia, y su impacto en el manejo económico del capital humano extranjero disponible.

\section{Referencias}

Accetturo, A. e Infante, L. (2013). Skills or culture? An analysis of the decision to work by immigrant women in Italy. IZA Journal of Migration, 2, 2. https://doi.org/10.1 186/2193-9039-2-2

ACNUR -Alto Comisionado de las Naciones Unidas para los Refugiados-. (2010). Manual para la Protección de los Desplazados Internos. https://www.acnur.org/5c6c3ae24.pdf

ACNUR -Alto Comisionado de las Naciones Unidas para los Refugiados-. (2020). Datos Básicos de los refugiados en el mundo. https://www.acnur.org/es/datos-basicos.html

Adsera, A. y Chiswick, B. (2007). Are there gender and country of origin differences in immigrant labor market outcomes across European destinations? J Popul Econ, 20, 495. https://doi.org/10.1007/s00148006-0082-y

Ariza, M. (2017). Capítulo 3. Escenarios migratorios, familias y hogares en el México contemporáneo. En J. Nájera, B. García y E. Pacheco (Coords.), Hogares y trabajadores en México en el siglo XXI (pp. 129-174). El Colegio de México. https://doi.org/10.2307/j.ctv4v321q.6

Banco de la República de Colombia. (2019). Tendencia a la baja de la demanda laboral: pausa en las ciudades y continúa en las áreas rurales. Reportes del Mercado Laboral, (12), 1-19. https://repositorio.banrep. gov.co/bitstream/handle/20.500.12134/9770/reportes\%20del\%20mercado\%20laboral\%20octubre\%20 19.pdf?sequence $=1$ \&isAllowed=y

Barone, G. y Mocetti, S. (2011). With a little help from abroad: The effect of low-skilled immigration on the female labour supply. Labour Economics, 18(5), 664-675. https://doi.org/10.1016/j.labeco.2011.01.010

Becker, G. S. (2009). Human capital: A theoretical and empirical analysis, with special reference to education. University of Chicago Press.

Becker, S. y Ferrara, A. (2019). Consequences of forced migration: A survey of recent findings. Labour Economics, 59, 1-16. https://doi.org/10.1016/j.labeco.2019.02.007

Bratsberg, B., Raaum, O. y Røed, K. (2018). Job Loss and Immigrant Labor Market Performance. Economica, 85(337), 124-151. https://doi.org/10.1111/ecca.12244

Caicedo, M. (2010). Migración, trabajo y desigualdad: los inmigrantes latinoamericanos y caribeños en Estados Unidos (No. 305.90691 C35). El Colegio de México. https://libros.colmex.mx/tienda/migraciontrabajo-y-desigualdad-los-inmigrantes-latinoamericanos-y-caribenos-en-estados-unidos/

Calderón-Mejía, V. e Ibáñez, A. M. (2016). Labour market effects of migration-related supply shocks: evidence from internal refugees in Colombia. J. Econ. Geography, 16(3), 695-713. https://doi.org/10.1093/jeg/ Ibv030 
Calderón, V., Gáfaro-González, M. e Ibañez-Londoño, A. (2011). Desplazamiento forzoso, participación laboral femenina y poder de negociación en el hogar: ¿Empodera el conflicto a las mujeres? (Documentos CEDE). Universidad de los Andes. https://ideas.repec.org/p/col/000089/009252.html

Caruso, G., Canon, G. y Mueller, V. (2019). Spillover effects of the Venezuelan crisis: migration impacts in Colombia. Oxford Economic Papers, 73(2), 771-795. https://doi.org/10.1093/oep/gpz072

Castillo, C. D. y García, J. (2019). Desempleo juvenil en Colombia: ¿la educación importa? Revista Finanzas y Política Económica, 11(1), 101-127. https://doi.org/10.14718/revfinanzpolitecon.2019.11.1.7

Colectivo loé. (2001). Mujer, inmigración y trabajo. Ministerio de Trabajo y Asuntos Sociales.

Congreso de la República de Colombia. (2006). Código de Infancia y Adolescencia. Ley 1098 de 2006. Diario Oficial N`46.446. https://www.procuraduria.gov.co/portal/media/file/Visi\%C3\%B3n\%20Mundial_ Codigo\%20de\%20Infancia\%202011\%281\%29.pdf

Cortés, K. E. (2004). Are refugees different from economic migrants? Some empirical evidence on the heterogeneity of immigrant groups in the United States. Rev. Econ. Stat., 86(2), 465-480. https://doi. org/10.1162/003465304323031058

Dagnelie, O., Mayda, A. y Maystadt, J. (2018). The Labor Market Integration of Refugees to the United States: Do Entrepreneurs in the Network Help? IZA Working Paper, 111, 257-272. https://doi.org/10.1016/j. euroecorev.2018.10.001

DANE -Departamento Administrativo Nacional de Estadística-. (2009). Metodología informalidad Gran Encuesta Integrada de Hogares. GEIH. https://www.dane.gov.co/files/investigaciones/boletines/ech/ ech_informalidad/metodologia_informalidad.pdf

DANE -Departamento Administrativo Nacional de Estadística-. (2014). Gran Encuesta Integrada de Hogares 2014. http://microdatos.dane.gov.co/index.php/catalog/MICRODATOS/about_collection/23/1

DANE -Departamento Administrativo Nacional de Estadística-. (2015). Gran Encuesta Integrada de Hogares 2015. http://microdatos.dane.gov.co/index.php/catalog/MICRODATOS/about_collection/23/1

DANE -Departamento Administrativo Nacional de Estadística-. (2016a). Gran Encuesta Integrada de Hogares 2016. http://microdatos.dane.gov.co/index.php/catalog/MICRODATOS/about_collection/23/1

DANE -Departamento Administrativo Nacional de Estadística-. (2016b). Metodología General Gran Encuesta Integrada de Hogares. GEIH. https://www.dane.gov.co/files/investigaciones/fichas/empleo/ metodologia_GEIH-01_V9.pdf

DANE -Departamento Administrativo Nacional de Estadística-. (2017). Gran Encuesta Integrada de Hogares 2017. http://microdatos.dane.gov.co/index.php/catalog/MICRODATOS/about_collection/23/1

DANE -Departamento Administrativo Nacional de Estadística-. (2018). Gran Encuesta Integrada de Hogares 2018. http://microdatos.dane.gov.co/index.php/catalog/MICRODATOS/about_collection/23/1

DANE -Departamento Administrativo Nacional de Estadística-. (2019). Gran Encuesta Integrada de Hogares 2019. http://microdatos.dane.gov.co/index.php/catalog/MICRODATOS/about_collection/23/1

De Flores, R. A. (2004). La dinámica migratoria colombo-venezolana: evolución y perspectiva actual. Geoenseñanza, 9(2), 191-202. https://www.redalyc.org/articulo.oa?id=360/36090205

Del Carpio, X. V. y Wagner, M. (2015). The Impact of Syrian Refugees on the Turkish Labor Market. World Bank Group. https://doi.org/10.1596/1813-9450-7402

Deryugina, T., Kawano, L. y Levitt, S. (2018). The economic impact of Hurricane Katrina on its victims: evidence from individual tax returns. American Economic Journal: Applied Economics, 10(2), 202-233. https://doi.org/10.1257/app.20160307 
Sociedad y Economía N 44 (Sep - dic 2021) / e-ISSN: 2389-9050 / e10410743

Inserción laboral de inmigrantes venezolanas, 2014-2019: ¿acumulación de desventajas?

Dustmann, C. y Schmidt, C. (2000). The wage performance of immigrant women: full-time jobs, part-time jobs, and the role of selection (IZA Discussion Paper 233). IZA. https://ideas.repec.org/p/iza/izadps/ dp233.html

Dustmann, C., Fasani, F., Frattini, T., Minale, L. y Schönberg, U. (2017). On the economics and politics of refugee migration. Econ. Policy, 32(91), 497-550. https://doi.org/10.1093/epolic/eix008

Farné, S., Guerrero, D. y Carvajal, C. (2013). La calidad del empleo en 23 ciudades colombianas. Universidad del Externado de Colombia. https://www.uexternado.edu.co/wp-content/uploads/2017/01/La-calidaddel-empleo-en-23-ciudades-colombianas.pdf

Ferreira, M. T. (2014). Las nociones de trabajo informal y trabajo precario en el análisis de la calidad del empleo en Colombia. Revista Lebret, (6), 29-58. https://doi.org/10.15332/rl.v0i6.1449

Flórez, C. E. (2003, 4-7 de junio). Migration and the urban informal sector in Colombia (ponencia). Conference on African Migration in Comparative Perspective, Johannesburg, South Africa. https://citeseerx.ist.psu. edu/viewdoc/download?doi=10.1.1.197.7013\&rep=rep 1 \&type=pdf

Gordon, M. M. (1964). Assimilation in American life: The role of race, religion, and national origins. Oxford University Press.

Hankivsky, O. (2014). Intersectionality 101. Institute for Intersectionality Research \& Policy. https:// bccampus.ca/wp-content/uploads/2020/07/Hankivsky-Intersectionality101-2014.pdf

Hausmann, R. y Nedelkoska, L. (2018). Welcome home in a crisis: effects of return migration on the nonmigrants' wages and employment. European Economic Review, 101, 101-32. https://doi.org/10.1016/j. euroecorev.2017.10.003

Ibáñez, A. M. y Velásquez, A. (2008). El impacto del desplazamiento forzoso en Colombia: condiciones socioeconómicas de la población desplazada, vinculación a los mercados laborales y políticas públicas. Organización de las Naciones Unidas, División de Desarrollo Social. https://repositorio.cepal.org/ handle/11362/6151

Lozano-Gracia, N., Piras, G., Ibáñez, A. y Hewings, G. (2010). The journey to safety: conflict-driven migration flows in Colombia. International Regional Science Review, 33(2), 157-180. https://doi. org/10.1177/0160017609336998

Mier-y-Terán, M. (1992). Descenso de la fecundidad y participación laboral femenina en México. Notas de población, 20(56), 143-171. http://repositorio.cepal.org/handle/11362/12953

Migración Colombia. (2020). Ingreso y permanencia de venezolanos en Colombia. https://www. migracioncolombia.gov.co/venezuela/

Morales, A. (2016). Capítulo 2. Migraciones laborales y la integración en los mercados de trabajo regionales. En C. Heredia (Coord.), El sistema migratorio mesoamericano (pp. 61-80). Colef; CIDE.

Morales, J. (2018). The impact of internal displacement on destination communities: Evidence from the Colombian conflict. Journal of Development Economics, (131), 132-150. https://doi.org/10.1016/j. jdeveco.2017.10.003

Ojeda-Pérez, F., García-Bueno, M. y González-Franco, R. (2019). Desarrollo sostenible del trabajador a través del trabajo decente. Sociedad y Economía, (38), 89-104. https://doi.org/10.25100/sye.v0i38.8026

Oliveira, O. y García, B. (1990). Trabajo, fecundidad y condición femenina en México. Estudios Demográficos y Urbanos, 5(3), 693-710. https://doi.org/10.24201/edu.v5i3.793

Parella, S. (2003). Mujer, inmigrante y trabajadora: la triple discriminación. Anthropos. https://www. torrossa.com/en/resources/an/4648614

Parella, S. (2004). La interacción entre clase social, género y etnia: el reclutamiento de mujeres inmigrantes en el servicio doméstico. Mientras Tanto, (93), 83-99. https://ddd.uab.cat/record/175950 
Pavajeau-Delgado, C. (2018). Migración y movilidad académica de mujeres colombianas cualificadas, transnacionalización de los afectos y asuntos de intimidad. Sociedad y economía, (34), 11-25. https:// doi.org/10.25100/sye.v0i34.5646

Pioré, M. (1983). Notas para una estratificación del mercado de trabajo. En L. Toharia (Coord.), El mercado de trabajo. Teorías y aplicaciones (pp. 193-211). Alianza Universidad.

Rodríguez, C. y Muñoz, J. (2018). Capital humano y factores culturales: Determinantes de la inserción laboral femenina en Chile. Perfiles latinoamericanos, 26(52), 1-22. https://doi.org/10.18504/pl2652-008-2018

Romero, A. M. (2013). Informalidad laboral en los centros urbanos de Colombia: ¿Depende del desplazamiento forzado? Pontificia Universidad Javeriana. https://cea.javeriana.edu.co/documents/153049/2786252/ Vol.13_4_2013.pdf/

Ruiz, I. y Vargas-Silva, C. (2017). Are refugees' labour market outcomes different from those of other migrants? Evidence from the United Kingdom in the 2005-2007 Period. Population, Space and Place, 23, e2049. https://doi.org/10.1002/psp.2049

Ruiz, I. y Vargas-Silva, C. (2018). Differences in labour market outcomes between natives, refugees and other migrants in the UK. J. Econ. Geography, 18(4), 855-885. https://doi.org/10.1093/jeg/lby027

Silva, A. (2012). Geografía del refugio, sobrevivencia económica y vida familiar de los desplazados forzados en Colombia. El Colegio de México.

Valencia, G. y Montoya, J. D. (2019). Desplazamiento forzado y mercado laboral en las principales ciudades de Colombia. Sociedad y Economía, (37), 50-70. https://doi.org/10.25100/sye.v0i37.6203

World Bank Group. (2018). Migración desde Venezuela a Colombia: Impactos y estrategia de respuesta en el corto y mediano plazo. World Bank Colombia. https://openknowledge.worldbank.org/ handle/10986/30651 